\title{
Modification of rubber surface with DLC thin films for low friction and self lubrication
}

\author{
X. L. Bui, Y. T. Pei, E. D. G. Mulder \& J. Th. M. De Hosson \\ Department of Applied Physics, \\ The Netherlands Materials Innovation Institute (M2i), \\ University of Groningen, The Netherlands
}

\begin{abstract}
Thin films of hydrogenated diamond-like carbon (DLC) have been deposited on hydrogenated nitrile butadiene rubber (HNBR) via magnetron-enhanced plasma chemical vapor deposition (ME-PCVD). Pre-deposition plasma treatment of HNBR substrate is proven to be crucial for the improvement of film performance due to enhanced interfacial adhesion. Moreover, enhancement of concurrent ion impingement via magnetron sputtering of graphite in poisoning condition raises further the adhesion and hardness of the films. The columnar structure and the crack network developed during deposition enhance the flexibility of DLC thin films and exhibit strain tolerance up to $5 \%$. After unloading from $50 \%$ strain stretch, thin DLC films of $\sim 300 \mathrm{~nm}$ thickness still adhere very well on the rubber substrates and no spallation or delamination is observed. The thin DLC film on $400 \mathrm{~V}$ plasma treated HNBR rubber exhibits very low coefficient of friction of 0.175 under dry sliding against $\varnothing 6 \mathrm{~mm}$ steel ball (compared to $>1$ of uncoated HNBR rubber). After tribotests even at high normal load of $3 \mathrm{~N}$, almost no damage can be seen on the films. Such tribological property is even better than that of $1 \mu \mathrm{m}$ thick DLC or Me-DLC coated rubbers.
\end{abstract}

Keywords: DLC film, rubber substrate, magnetron sputtering, flexibility, tribology.

\section{Introduction}

Rubbers are widely used in various engineering applications. Nonetheless, rubbers exhibit very high friction when sliding against other materials. It is known that contact rubber seals are the major source of friction of lubrication 
systems or bearings, which may take $50-70 \%$ of the total friction loss. The high friction of rubbers is due to the adhesion-prone of rubber to the counterpart, the ploughing of asperities of harder counterpart (steel, glass, etc.) on the rubbers surface and the so-called "hysteresis" that relates to the viscoelastic nature of rubbers [1]. Besides the high friction, wear of rubbers is usually severe and mostly relates to adhesive and abrasive wear. So far, there are two solutions that can be used to reduce the friction and to enhance the wear resistance of rubber components: lubrication and coating. As to the first solution, oil or grease is applied to improve the surface lubricity of rubbers. However, it has drawbacks such as the degradation of lubricants and environmental pollution problems. For the second solution, a layer of an appropriate wear-resistant material is coated on the working surfaces of rubber components in order to protect the rubbers from wear and to reduce the friction. The development of advanced deposition methods makes the coating solution very promising. To coat rubbers, two problems have to be considered: (1) The deposition temperature must not exceed the maximum working temperatures of various rubber materials; (2) The use of chemical substance, especially the toxic ones, in cleaning rubbers before deposition should be limited to prevent pollution. For a good performance, a coating deposited on rubbers should have (1) strong adhesion to rubber substrates, (2) sufficient flexibility to adapt large strain of rubbers under applied loads and (3) good wear resistance and low friction. According to these criteria, efforts in finding appropriate coatings for rubbers lead to diamond-like carbon (DLC) and DLC-based thin films, which have been well investigated and industrialized for decades but mostly used on stiffer substrates such as metallic alloys or Si-wafers [2].

Several deposition techniques such as RF-plasma deposition [3,4], filtered-arc deposition [5,6], femtosecond-pulsed laser deposition [7] have recently been applied to deposit DLC films on various kinds of rubbers. In general, the coefficient of friction (CoF) of DLC coated rubbers was reported to be much lower than uncoated ones (by more than 2 times). However, the loads applied in these works were usually lower than $2 \mathrm{~N}$ (with $ø 6 \mathrm{~mm} 100 \mathrm{Cr} 6$ steel ball counterparts) since at higher loads the films were damaged after a few rotation revolutions. Also, the microstructure of these DLC-coated rubbers has not been well investigated. Recently, we deposited metal-doped DLC (Me-DLC) via reactive magnetron sputtering on rubbers [8,9] and successfully decreased the coefficients of friction from more than 1 of uncoated rubber to less than 0.22 for coated ones (1N load, $ø 6 \mathrm{~mm} 100 \mathrm{Cr} 6$ steel ball counterpart). Especially, under high normal load of $5 \mathrm{~N}$, the films were still functional after the tests of 10000 revolutions with coefficients of friction less than 0.24 . It has been revealed that, due to high coefficients of thermal expansion (CTE) of rubbers, a segmented structure composed of crack network and patches is formed in thick DLC-based films and the size of the film patches is mainly depending on the difference in the CTEs between the films and rubbers and the temperature variation during deposition [10]. The crack network is in fact beneficial for the enhancement of film flexibility. We also recognized that thick DLC film ( $1 \mu \mathrm{m}$ or thicker $)$ may not be necessary for a good tribological performance of coated rubbers since 
wear of DLC film under "soft" contact due to the very low modulus of rubbers is negligibly small. The most critical issues that determine the performances of DLC-coated rubber are the interfacial adhesion and film flexibility.

In this work, we deposit a thin layer (about $300 \mathrm{~nm}$ ) of DLC on HNBR rubber by sputtering of graphite targets in $\mathrm{Ar} / \mathrm{C}_{2} \mathrm{H}_{2}$ plasma. For enhancement of film adhesion, plasma pre-deposition treatment of HNBR and its influence on the performance of the coated rubber are investigated. In addition, a simple and effective method for removal of the wax on rubber surfaces is introduced.

\section{Experimental}

Black hydrogenated nitrile butadiene rubber (HNBR) sheet of $2 \mathrm{~mm}$ thickness was used as substrate in this study. The commercial HNBR sheet has oil contamination and a thin wax layer on the surfaces, likely from the rolling process. The HNBR substrates of $40 \times 40 \mathrm{~mm}^{2}$ size were first cleaned by soap in an ultrasonic cleaner then rinsed carefully with demineralized water. Thereafter, wax removal was carried out in ultrasonic tank with hot demineralized water (80$90^{\circ} \mathrm{C}$ ). This washing process with hot water was repeated three times. After that the HNBR substrates were dried in a centrifugal machine and then heated up to $120^{\circ} \mathrm{C}$ for $15 \mathrm{~min}$ in order to evaporate all absorbed water. The substrates were cooled down in ambient air to room temperature before being loaded into the deposition chamber. The instrumental modulus of HNBR rubber, determined by the method described in [8], is $15.2 \mathrm{MPa}$ and its surface roughness is $0.35 \mu \mathrm{m}$ measured after wax removal using laser confocal microscope.

Plasma etching pre-treatment of rubber substrates and deposition of DLC films were carried out in a Teer UDP400/4 closed-field unbalanced magnetron sputtering system, which was configured of four magnetrons evenly distributed along the round chamber of $400 \mathrm{~mm}$ diameter with two graphite targets opposite to each other (the other two magnetrons were off-power). HNBR substrates were etched in $250 \mathrm{kHz}$ pulsed-DC Ar plasma for $20 \mathrm{~min}$ at different bias voltages $(-200 \mathrm{~V},-300 \mathrm{~V}$ and $-400 \mathrm{~V})$. The deposition process followed immediately after the plasma etching pre-treatment. DLC films were deposited for $23 \mathrm{~min}$ by sputtering two graphite targets $(99.9 \%)$ of $249 \times 133 \mathrm{~mm}^{2}$ size in $\mathrm{Ar} / \mathrm{C}_{2} \mathrm{H}_{2}$ plasma. The current applied on the graphite targets was fixed at $0.8 \mathrm{~A}$ each, corresponding to an average voltage of $480 \mathrm{~V}$ and average power of $384 \mathrm{~W}$. The gas flow rate was set at $\mathrm{Ar} / \mathrm{C}_{2} \mathrm{H}_{2}=15 / 10 \mathrm{sccm}$ and the process pressure of $3 \times 10^{-3}$ mbar was kept constant during deposition via throttle control. The HNBR substrates clamped $80 \mathrm{~mm}$ apart from the graphite targets were biased with pulsed DC $(250 \mathrm{kHz}, 75 \%$ duty cycle) at $-200 \mathrm{~V}$ and the sample holder was rotated at a speed of $5 \mathrm{rpm}$ during the deposition. The maximum deposition temperature of $102 \pm 2^{\circ} \mathrm{C}$ was measured in situ with a surface thermometer (model 574CM, PTC instruments, Los Angeles, USA) laid in a cup holder that was fixed at the same position as the HNBR substrates on the sample holder.

The surface morphology and wear track of coated rubber after tribotests were characterized with scanning electron microscope (SEM) (Philips FEG-XL30). The film flexibility is estimated via stretch test with a tensile stage inside the 
SEM. The coated rubber sheets were glued onto $ø 30 \mathrm{~mm}$ polished M2 steel discs for tribotests. The tests were performed at $20 \sim 23^{\circ} \mathrm{C}$ on a CSM tribometer with ball-on-disc configuration. The counterpart was $\varnothing 6 \mathrm{~mm} 100 \mathrm{Cr} 6$ steel balls of hardness HRC 60-62. All the tribotests were carried out at sliding velocity of 10 $\mathrm{cm} / \mathrm{s}$ and a constant humidity of $35 \pm 1 \%$ kept with a humidity regulator.

\section{Results and discussion}

Fig. 1 shows the effect of pre-deposition treatment on the surface morphology of HNBR rubber. Before wax removal, the surfaces of the rubber are almost fully covered by a layer of wax (Fig. 1a), which could not be removed in the previous step (ultrasonic cleaning with soap). After wax removal using hot water, no wax blots can be seen but a powdery morphology observed (Fig. 1b). The plasma treatment of rubber substrates further removes the contaminants (at molecule level) and modifies the surface morphology of the rubber. As seen in Figs. 1c and $1 \mathrm{~d}$, pitted areas are formed on the rubber surface due to plasma etching. The density of pitted areas is proportional to the voltage applied during plasma treatment. After $-400 \mathrm{~V}$ plasma etching, a large amount of finer fillers resulted from partially etching are exposed on the surface and the original rubber "skin" was fully peeled off.
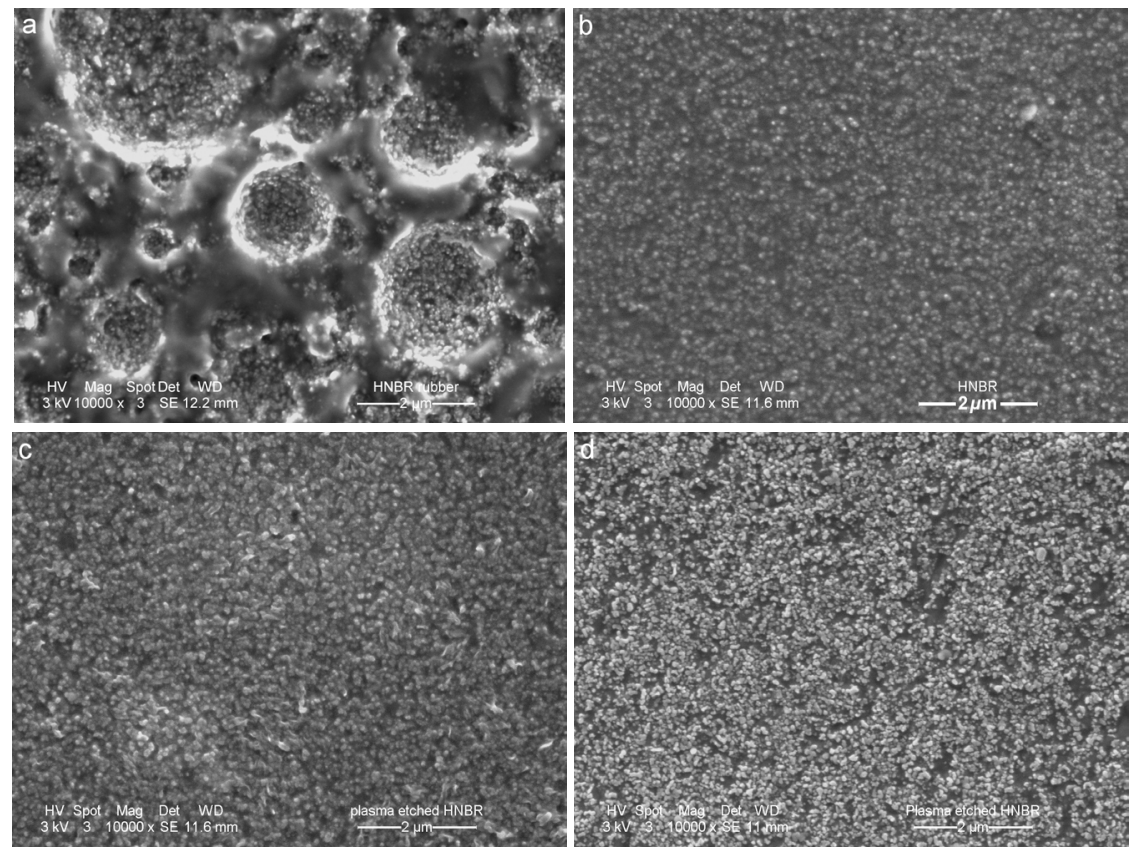

Figure 1: $\quad$ Surface morphology of HNBR substrates: (a) before and (b) after wax removal by hot water; after further etching treatment for 20 min with $-200 \mathrm{~V}$ Ar-plasma (c) and -400V Ar-plasma (d), respectively. 

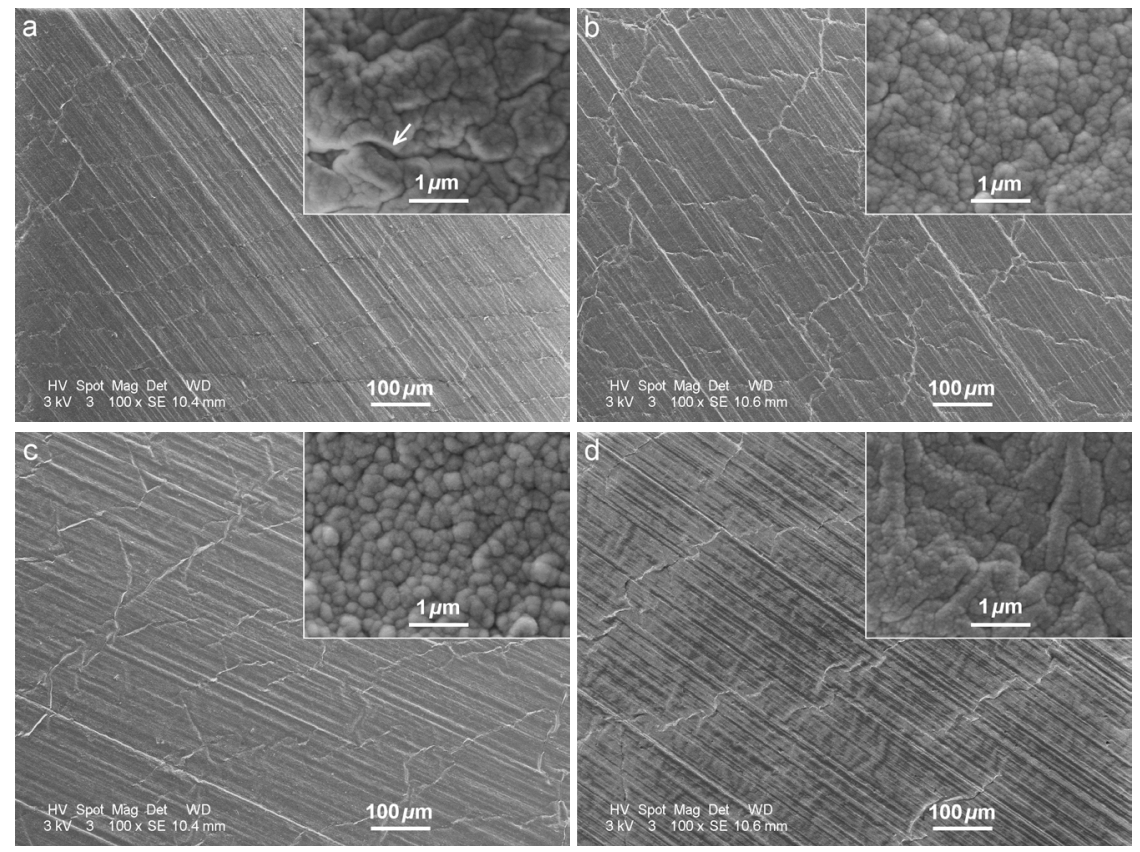

Figure 2: $\quad$ Crack network and surface morphology of DLC films on HNBR substrate pre-treated differently: (a) without plasma treatment; etched for $20 \mathrm{~min}$ in -200V Ar-plasma (b), -300V Ar-plasma (c) and -400V Ar-plasma (d), respectively.

The surface morphology of DLC film coated HNBR substrates with different regimes of plasma pre-treatment is shown in Fig. 2, with inset of high magnification view. The overview shows random crack networks formed in all the DLC films, as well as dense and coarse rolling scratches originated from fabrication of rubber sheet. These crack networks are different from the ones previously observed on $1 \mu \mathrm{m}$ thick Me-DLC films deposited on HNBR rubber under the same bias voltage of -200V [10]. The differences concern two aspects: (1) The cracks are not open and (2) no clear segmented structure is seen. It has been proven that the formation of open cracks and segmented structure of films on HNBR is directly related to the large difference in the CTE of HNBR $\left(230 \times 10^{-6} \mathrm{~K}^{-1}\right)$ and DLC films $\left(2.3 \times 10^{-6} \mathrm{~K}^{-1}\right)$ and the squeeze between the film segments during cooling down from the deposition temperature to room temperature. Therefore, such differences can be attributed to the lower deposition temperature controlled in this study and smaller film thickness $(280-360 \mathrm{~nm}$ versus $1 \mu \mathrm{m}$ in Ref. [10]), thus lower stresses in the thin DLC films. From Fig. 2, it can be seen that the film on the rubber substrates pre-treated in higher voltage plasma has less dense cracks in comparison with that on untreated rubber. The main reason considered is the temperature difference of the substrates prior to and under deposition. The starting temperature of the substrate was $21^{\circ} \mathrm{C}$ with no treatment and $29^{\circ} \mathrm{C}, 49^{\circ} \mathrm{C}$ and $85^{\circ} \mathrm{C}$ right after plasma etching at substrate 
voltage of $-200 \mathrm{~V},-300 \mathrm{~V}$ and $-400 \mathrm{~V}$, respectively. During the onset of deposition, the temperature of the substrates gradually increased to the steady deposition temperature of $102^{\circ} \mathrm{C}$ due to ion impingement. Apparently, a smaller increase of temperature during the onset of deposition results in lower tensile stress in the growing film and thus less cracks. In this sense, pre-deposition heating of rubber substrates close to the deposition temperature is helpful to reduce the density of crack network. On the other hand, crack network is beneficial for flexibility and release of the compressive stress built up in a film during cooling after deposition.

At high magnification, it can be seen that the DLC film on $-400 \mathrm{~V}$ Ar-plasma pre-treated HNBR substrate (inset of Fig. 2d) has the densest and finest morphology with domains of worm-like shapes, likely attributed to the strong etching effect on the substrate. The fine and dense feature of film morphology is the result of finer fillers exposed on rubber surface after plasma treatment (Fig. 1d) and smaller thermal mismatch resulted from the smallest temperature difference. The morphology of the films on $-200 \mathrm{~V}$ and $-300 \mathrm{~V}$ plasma pre-treated HNBR substrates (inset of Figs. $2 b$ and $2 c$ ) is similar, with coarser and well defined columns characterized by dome head compared to that of the film on $-400 \mathrm{~V}$ plasma pre-treated substrate. The DLC film on untreated substrate (inset of Fig. 2a) exhibits micro-gaps (marked with an arrow), which divide the film into micro-domains. This probably relates to the highest thermal stress built up in the growing film due to the largest temperature difference during the onset of deposition.
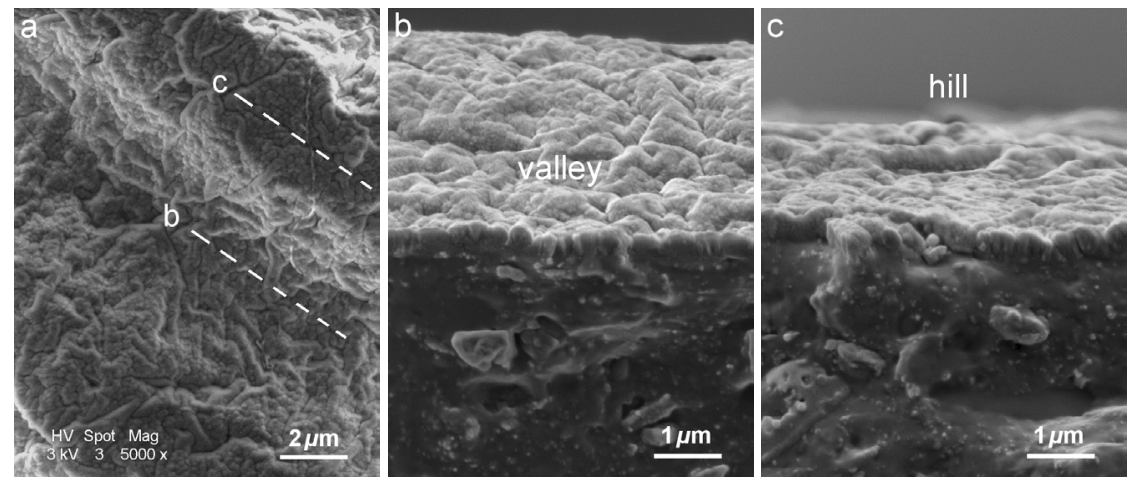

Figure 3: (a) Surface morphology of DLC film deposited on $-400 \mathrm{~V}$ Arplasma pre-treated HNBR; fracture cross section of the DLC film coated HNBR along a valley (b) and a hill (c).

The thickness of DLC films is not very homogeneous as examined at the fracture cross sections of the coated rubbers. Due to the rolling scratches formed on the rubber surfaces during manufacturing, the concave (the "valley") and convex (the "hill") areas are easily recognized after film deposition. As seen in Fig. 3a where the location of representative cross sections of DLC coated rubber is marked, the film on the valley (thickness of about $280 \mathrm{~nm}$ ) is thinner than that 
on the hill (thickness of about $360 \mathrm{~nm}$ ), as shown in Figs. 3b and 3c. It is attributed to the shadowing effect. All thin DLC films deposited in this study have columnar structure (like the one shown in Fig. 3). As investigated in our previous work [8], due to rough morphology and high CTE of rubbers, DLC and DLC-based films typically have columnar structure when deposited on rubber substrates unless ion impingement of high intensity is used.

To examine the interfacial adhesion strength and flexibility of DLC films on HNBR substrates pre-treated differently, tensile tests (stretch) and in situ SEM observation were performed. When the coated rubber is stretched, the strain tolerance of the columnar structure and existing cracks may compensate the applied strain at the beginning of the test. When the strain is beyond 5\%, new cracks initiate and propagate perpendicular to the stretch direction. The amount of cracks increases with increasing strain. Fig. 4 shows the morphology of DLC coated rubbers (untreated and $-400 \mathrm{~V}$ plasma pre-treated) stretched to $20 \%$ and $50 \%$ strain, and after unloading from $50 \%$ strain. At $20 \%$ strain (Figs. $4 \mathrm{a}$ and $3 d$ ), considerable amount of new cracks form and open. These cracks together with the cracks parallel to the stretch direction formed due to the Poisson's shrinkage of rubber divide the DLC film into rectangular segments.

At high strain of $50 \%$, new generations of cracks form and separate the segments further (Figs. $4 \mathrm{~b}$ and $3 \mathrm{e}$ ). Also, the opening of the cracks is widened as stretch goes on. At higher strains $(>50 \%)$, the number of such cracks does not considerably increase but only continuous widening of existing cracks is observed. It is recognizable that the crack spacing in the film deposited on untreated rubber is much larger than that of film on plasma pre-treated one at the same levels of strain (compare Fig. $4 \mathrm{a}$ with $3 \mathrm{~d}$ and $3 \mathrm{~b}$ with $3 \mathrm{e}$, respectively). It has been proven that, under tensile condition, the interfacial shear strength of a film/substrate system is inversely proportional to the crack spacing [11]. Therefore, it can be concluded that DLC film on -400V Ar-plasma pre-treated HNBR has stronger adhesion than that on untreated HNBR. After being unloaded from $50 \%$ strain, no delamination or damage can be observed on the films. However, the cracks generated during stretch can be easily recognized in the film on untreated HNBR substrate (Fig. 4c), due to residual opening. In contrast, it is hard to observe these cracks in the film on the pre-treated substrate (Fig. 4f). It is clear that, at 50\% strain, the cracks in the film on untreated HNBR are much wider $(\sim 10 \mu \mathrm{m}$, Fig. $4 \mathrm{~b})$ compared to that of film on the pre-treated rubber $(<5 \mu \mathrm{m}$, Fig. $4 \mathrm{~d})$. In addition, a few tiny chips of DLC film are formed and delaminated from untreated HNBR substrate after unloading (Fig. 4c). In view of tribology, these open cracks worsen the performance of films since they are the cause of wear debris generated due to impact of counterpart with the sharp edge of crack banks during sliding [9]. The results of stretch tests confirm that the DLC films reported here have good flexibility since they can adapt the deformation of the rubber substrate up to $5 \%$ strain without crack generation. At high strain of $50 \%$, the films exhibit no spallation, indicating a strong adhesion to the plasma-treated HNBR substrate. It should be noted that DLC films deposited on steel substrates are heavily cracked and already peeled off at $4 \%$ strain [12]. 

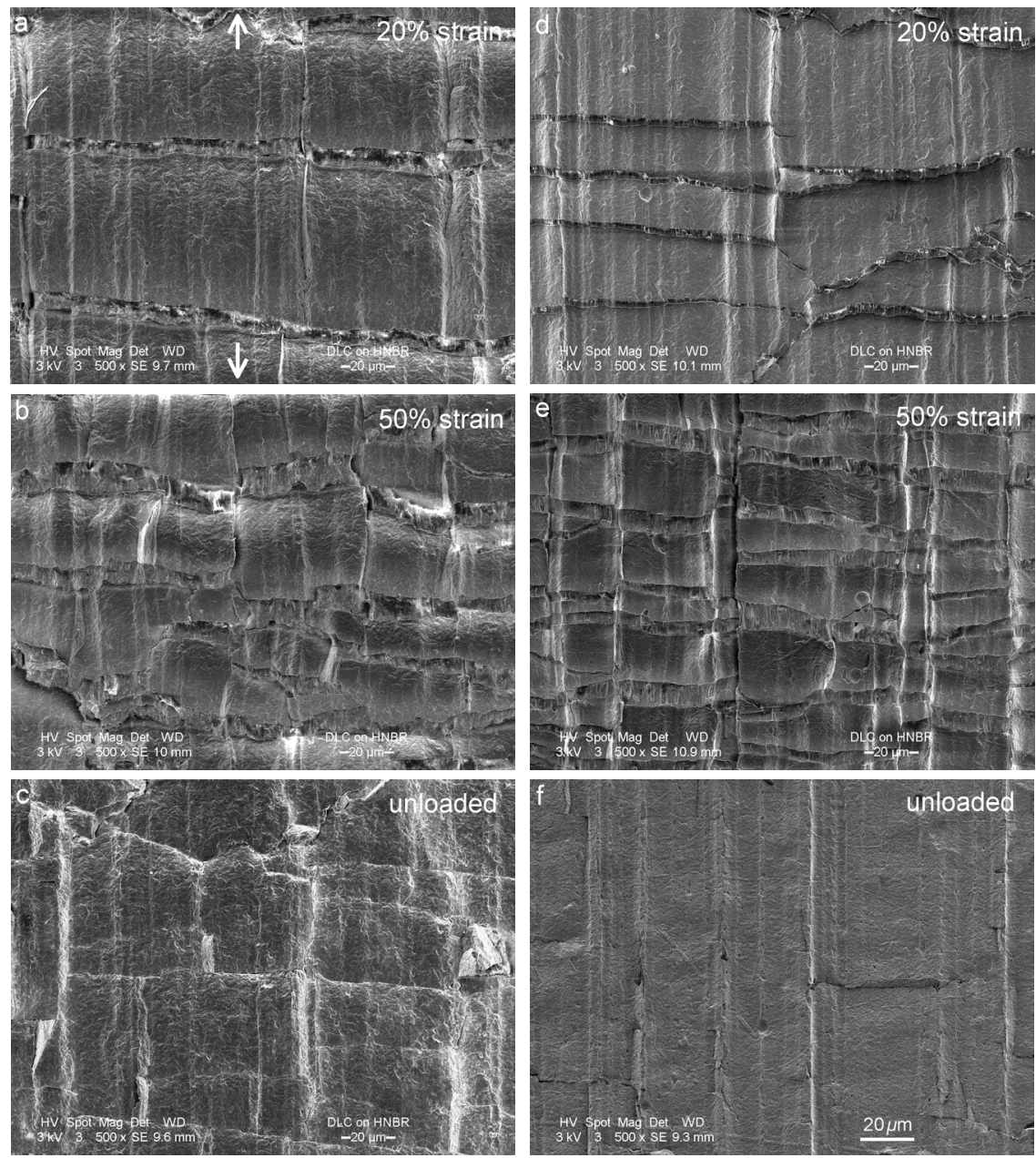

Figure 4: $\quad$ Morphology of DLC film deposited on untreated (left column) and $-400 \mathrm{~V}$ Ar-plasma pre-treated HNBR (right column) after being stretched to $20 \%$ strain (a,d), $50 \%$ strain $(\mathrm{b}, \mathrm{e})$ and unloaded from the maximum strain $(\mathrm{c}, \mathrm{f})$. A pair of arrows indicates the stretch direction.

The CoF of DLC films deposited on untreated and -400V Ar-plasma pretreated HNBR substrates are shown in Fig. 5. The CoF of uncoated HNBR rubber $(>1)$ was measured in our previous work [8] and not included here. At 1N load, the CoF of two DLC films is very low. By the end of the tests, it is 0.175 for the film deposited on $-400 \mathrm{~V}$ plasma pre-treated HNBR and is about 0.18 for the films on untreated HNBR. Such low CoFs are mainly attributed to the chemical inertness of DLC film that prevents adhesion onto the contact surface of the counterpart, rather than its graphitization. Surface graphitization of DLC 
films on rigid substrates (like metals, $\mathrm{Si}$, etc.) is considered as one of the major mechanisms operating for ultralow CoF $[13,14]$. However, it does not work in the case of softer substrates such as rubber because the contact stress $(<10 \mathrm{MPa})$ is not high enough to induce the process of graphitization [10]. At the end of tribo-test, the CoF of films on untreated rubber slightly increase, whereas that of the film on $-400 \mathrm{~V}$ plasma pre-treated rubber is almost constant. At a high applied load of $3 \mathrm{~N}$, the $\mathrm{CoF}$ is higher compared to that measured at $1 \mathrm{~N}$ load. Also, the increase in the $\mathrm{CoF}$ of the films on untreated rubber can be easily recognized, especially, at the stage after 6000 laps. This is an indication of partial film damage or formation of wear debris (see Fig. 6b); but the film is still functional since the CoF of these films is still low (about 0.22) at the end of the tests and exhibits no sudden increase in the whole course of tests. On the contrary, the CoF of the film on $-400 \mathrm{~V}$ plasma pre-treated HNBR does not considerably increase and maintains at a lower value of about 0.2 till the end of the test.

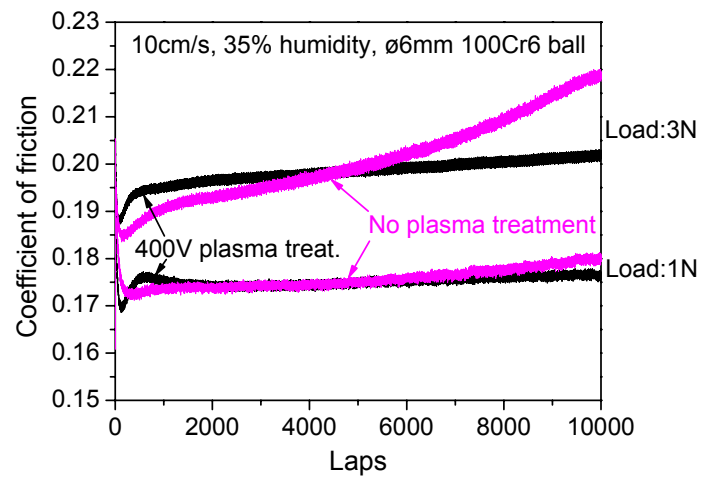

Figure 5: Coefficient of friction of DLC films deposited on untreated and 400V Ar-plasma pre-treated HNBR substrates, with tribo-test condition indicated.

Fig. 6 shows wear track on DLC film coated HNBR rubbers after tribotest. In the case of DLC film on $-400 \mathrm{~V}$ plasma pre-treated HNBR (Fig. 6a), the wear track is hardly visible except the increased density of random micro-cracks observed under close inspection, so that two dashed lines are added to indicate the borders of the wear track for a better view. The generation of micro-cracks on the wear track is attributed to the large localized bending deformation of the rubber substrate at the high normal load of $3 \mathrm{~N}$ to adapt the spherical geometry of the counterpart. In fact, almost no wear is observed on the track. Only tiny polished spots of micrometric size are observed, as marked by an arrow in the inset. For the films on untreated (Fig. 6b) HNBR substrates, the wear tracks are obvious, with dense bright dots and many cracks within and beside the wear track. Tensile-type (arc-shaped) Hertzian cracks of regular spacing form within the wear track, concave towards the sliding direction of counterpart ball. Forward chevron cracks nucleate at the borders of the wear track. All these cracks hardly form at $1 \mathrm{~N}$ load and are attributed to the large deformation of 
rubber substrate at higher load and especially poorer adhesion of DLC film on untreated or weak plasma pre-treated HNBR on one hand. The less dense structure of straight column characterized by dome head on top view may cause an easy propagation of cracks through the column boundary on the other hand, in comparison with the curved worm-like microstructure of DLC film on $-400 \mathrm{~V} \mathrm{Ar-}$ plasma pre-treated HNBR. The bright dots are micro-chipping, the source of wear debris (see the inset of Fig. 6b). Indeed, wear of DLC film is evident as the original growth features are fully worn out. This explains the increase in the CoF of these two films after 6000 laps as seen in Fig. 5. In comparison with thick DLC films that were totally damaged after a few testing laps under the same testing conditions ( $3 \mathrm{~N}$ load and $\varnothing 6 \mathrm{~mm}$ steel ball) [4], the thin DLC films in this study exhibit superior tribological properties, especially the film deposited on $400 \mathrm{~V}$ plasma pre-treated HNBR. Such excellent performance is attributed to the enhanced adhesion, good flexibility, refined microstructure and adequate hardness of thin DLC films, via proper plasma treatment of rubber surfaces.
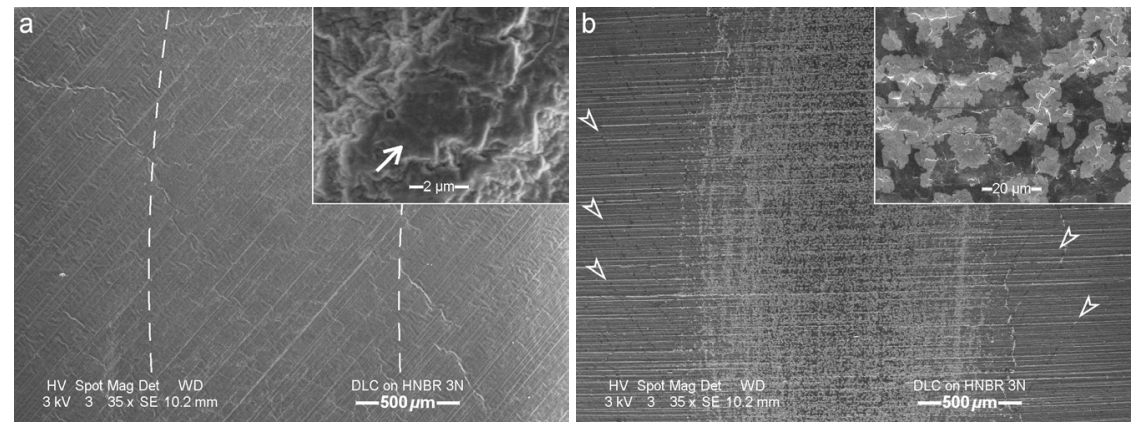

Figure 6: Wear track of DLC film coated HNBR after tribotest under 3N load: (a) $-400 \mathrm{~V}$ Ar-plasma pre-treated HNBR and (b) untreated HNBR. The hollow arrows indicate the chevron cracks beside the wear tracks.

\section{Conclusion}

Thin DLC films have been deposited on rough HNBR rubber by sputtering of graphite targets in $\mathrm{C}_{2} \mathrm{H}_{2} / \mathrm{Ar}$ plasma. Hot water and plasma treatment are proven to be very effective and environment-friendly in removal wax and other contaminants on rubber surface. Plasma treatment modifies the film morphology due to: (1) modification of the rubber morphology and (2) changing the temperature at which the deposition starts. The network of cracks and columnar structure make the DLC films flexible. Plasma pre-treatment of the rubber substrate enhances the interfacial adhesion. After stretched to $50 \%$ strain and unloading, the DLC films still adhere very well on the rubber substrates and no spallation or delamination was observed. The thin DLC film deposited on $-400 \mathrm{~V}$ plasma pre-treated rubber exhibits very low $\mathrm{CoF}(0.175$ at $1 \mathrm{~N}$ load and 0.20 at $3 \mathrm{~N}$ load), suitable for industrial applications. The wear resistance of this film is 
very good, no damage but only mildly polished tiny spots can be seen on the "hill" positions. Such tribological behavior is even better than that of $1 \mu \mathrm{m}$ pure DLC or Me-DLC coated rubbers.

\section{Acknowledgements}

This research was carried out under the project number MC7.06247 in the framework of the Research Programme of The Netherlands Materials Innovation Institute (M2i), the former Netherlands Institute for Metals Research, Delft, The Netherlands. Dr. X.B. Zhou in the Department of Science and Technology, SKF Research and Development B.V., The Netherlands is thanked for his valuable discussion and input.

\section{References}

[1] B.N.J. Persson, J. Phys. Condens. Matter. 18 (2006) 7789

[2] A. Matthews, S.S. Eskildsen, Diamond Relat. Mater. 3 (1994) 902

[3] T. Nakahigashi, Y. Tanaka, K. Miyake, H. Oohara, Tribol. Int. 37 (2004) 907

[4] Y. Aoki, N. Ohtake, Tribol. Int. 37 (2004) 941

[5] H. Takikawa, N. Miyakawa, S. Minamisawa, T. Sakakibara, Thin Solid Films 457 (2004) 143

[6] N. Miyakawa, S. Minamisawa, H. Takikawa, T. Sakakibara, Vacuum 73 (2004) 611

[7] S. Yoshida, M. Okoshi, N. Inoue, J. Phys.: Conference Series 59 (2007) 368

[8] Y.T. Pei, X.L. Bui, X.B. Zhou, J.Th.M. De Hosson, Surf. Coat. Technol. 202 (2008) 1869

[9] Y.T. Pei, X.L. Bui, X.B. Zhou, J.Th.M. De Hosson, J. Vac. Sci. Technol. A 26 (2008) 1085

[10] X.L. Bui, Y.T. Pei, J.Th.M. De Hosson, Surf. Coat. Technol. 202 (2008) 4939

[11] D.C. Agrawal, R. Raj, Acta Metall. 37 (1989) 1265

[12] H.W. Choi, K-R. Lee, R. Wang, K.H. Oh, Diamond Relat. Mater. 15 (2006) 38

[13] Y. Liu, A. Erdemir, E.I. Meletis. Surf. Coat. Technol. 86-87 (1996) 564

[14] Y.T. Pei, D. Galvan, J.Th.M. De Hosson. Acta Mater. 53 (2005) 4505. 